\title{
Structural Vibrations of Wooden House Walls
}

$$
\text { by }
$$

Åsa Bolmsvik

Reprinted from

\section{BUILDING ACOUSTICS}

Volume $13 \cdot$ Number $4 \cdot 2006$ 


\title{
Structural Vibrations of Wooden House Walls
}

\author{
Åsa Bolmsvik \\ School of Technology and Design, Växjö University, \\ SE-35195 Växjö, Sweden \\ asa.bolmsvik@vxu.se
}

(Received 8 June 2006 and accepted 11 October 2006)

\begin{abstract}
The flanking transmission between apartments due to a structure borne source is studied. The apartments studied were two-storey houses with a wooden framework. Acoustic measurements are often made in new built apartments to make sure that they fulfil the building regulations. Traditional measurements give no information about the contribution of the surrounding walls to the sound transmission.
\end{abstract}

This paper describes a method of measuring flanking transmission. The acceleration levels on the receiving parts in the apartment below the source are studied. Thereby the contribution to the sound pressure in the room from each flanking part can be distinguished.

Keywords: Wooden framework, Impact noise, Vibration, Accelometer measurement

\section{INTRODUCTION}

In Sweden there is much interest in building multifamily houses with a timber frame, but with some reservations among the construction firms. This is mainly because building regulations prohibited timber frames until 1994 [1] and the knowledge and experience of this building method for higher houses is limited. In 1994 the building regulations were changed to allow construction of multistory houses with a timber frame. In Sweden, most single-family houses are built with timber framing, so the knowledge about wood as construction material is good. A remaining concern is that timber-framed houses may not fulfil the building regulations concerning sound transmission between apartments [2].

A small housing scheme has been built in Växjö in southern Sweden. The housing area consists of seven two-storey houses, each one with four apartments, see Figure 1. The houses have a wooden framework, with a well-defined prefabricated construction. The floor system is a semi-homogenous solid wood system [3]. It is not heavy, but the distance between the beams $(180 \mathrm{~mm})$ are less than in traditional wood frame systems. The walls are of a traditional wood frame system. The outer walls are 2-layered and the inner walls are one-layered (the centre distance between the studs are approximately $450 \mathrm{~mm})$. 


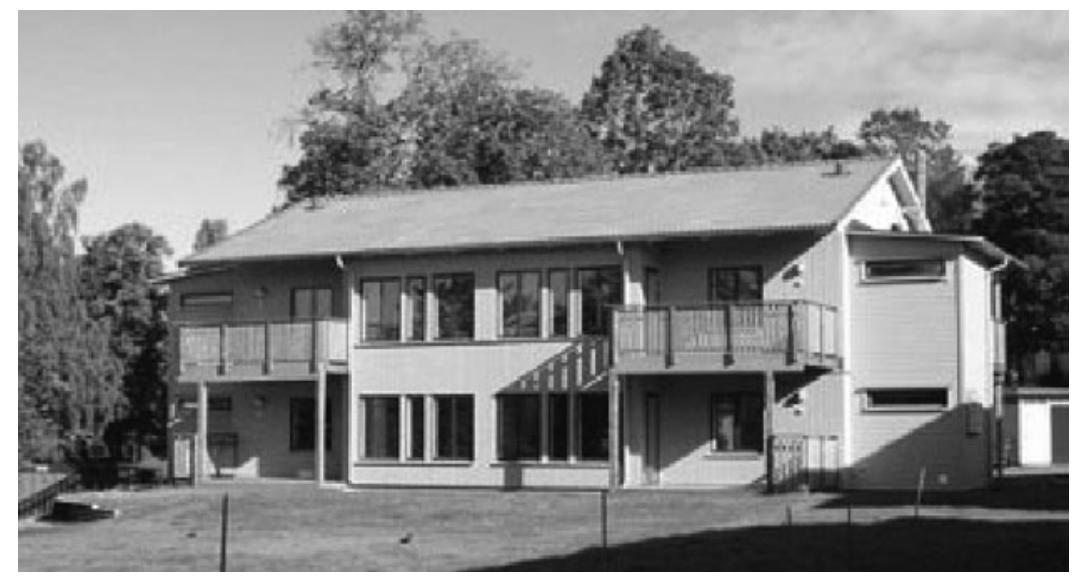

Figure 1. A two-floor house in the area Kv. Kampen in Växjö with four apartments

In order to comply with the regulations regarding sound insulation between apartments, acoustic measurements are performed [2]. The traditional measurements give no information about which parts of the surrounding walls or roof contribute to the total sound transmission. The flanking transmission is usually studied by covering all the flanking parts not studied with isolating material. Thereby the contribution from one single flanking area can be obtained. This is time-consuming and not totally reliable.

In this paper another way of measuring flanking transmission is presented. This measurement gives information about the distribution of acceleration due to structure borne sound between two apartments. If one wall type in the receiving apartment has much larger acceleration level than the others, a detailed study can be undertaken. The aim of the method is to obtain more information about the propagation of vibration in order to create structures and connections that do resist the propagation.

\section{TEST HOUSING}

The flanking transmission in a two-floor house in Växjö Sweden, was studied by means of an impact source and accelometer measurements. The vibrations was generated by a source on the second floor and transmitted to the surrounding walls in the receiving room on the first floor. The impact source used to generate the vibrations was an ISO standard tapping machine [2].

In the house studied, called $\mathrm{C} 1$, the tests were conducted in a small room of floor area $8.1 \mathrm{~m}^{2}$, see Figure 2. This room has four types of walls, inner and outer bearing wall, party wall and an interior wall. The acceleration levels on each wall type were measured. The elevations of the walls and the design of the connections can be seen in Figure 3. 


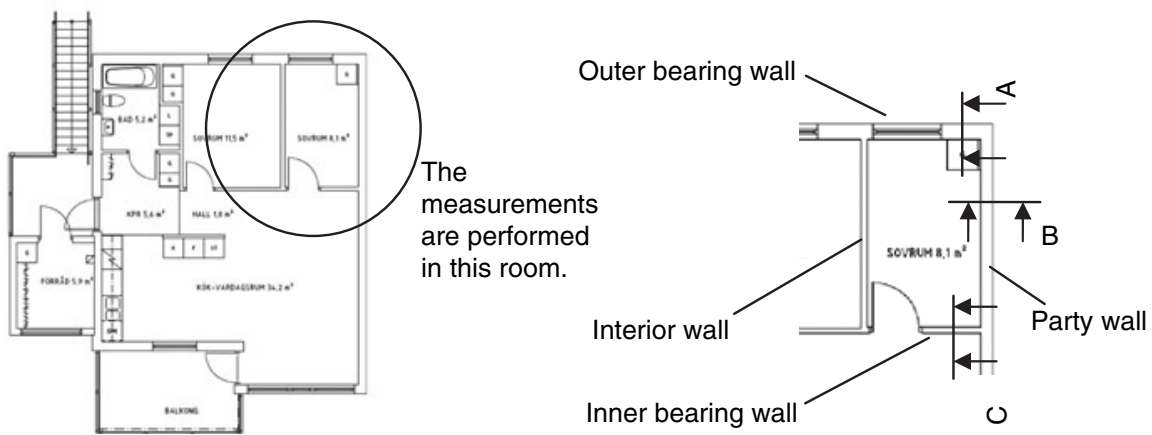

Figure 2. General layout over one apartment (left) and the wall types in the studied rooms (right).

\section{TEST PROCEDURE}

The standard tapping machine was placed at two positions in the room on the second floor one in the middle and one in a corner of the room, see Figure 4. For each source position, the accelerations were measured at 7 positions on the upper floor in house $\mathrm{C} 1$. In addition, the accelerations were measured at 24 positions on the walls and 5 positions on the roof, see Figure 5. The points were placed randomly in the central parts of the

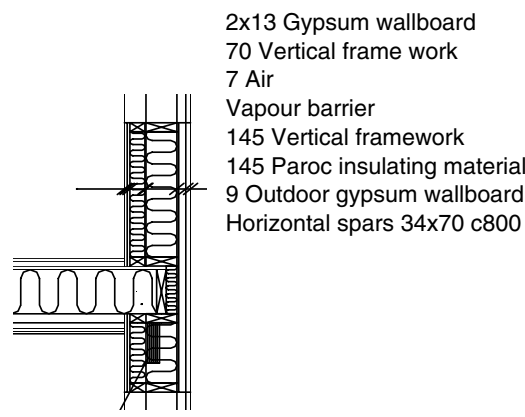

The outer bearing wall, in house C3.

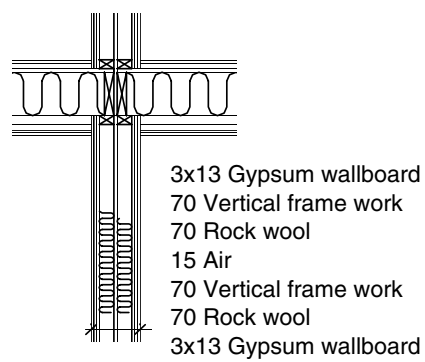

The party wall

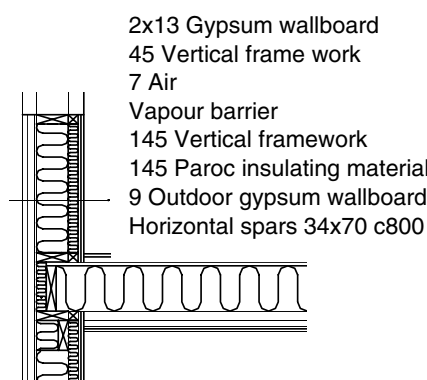

The outer bearing wall, in house C1.

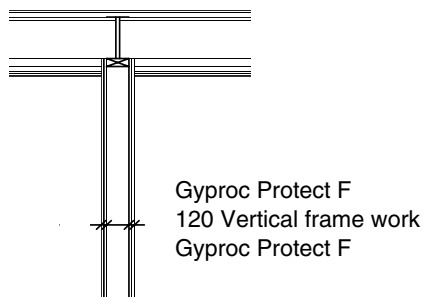

The inner bearing wall

Figure 3. Side elevation of the different wall types in house $\mathrm{C} 1$ and $\mathrm{C} 3$. 


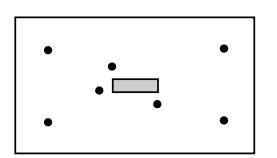

Test position a

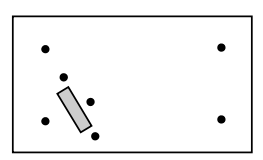

Test position $b$

Figure 4. Tapping machine positions and acceleration measurement positions on the floor in house $\mathrm{C} 1$.

walls and of the roof. On the walls, half of the measuring points were on the wall studs and half at positions between.

The accelerations were also measured in another house in the same area, called C3, where the construction is the same as in house $\mathrm{C} 1$ except for a thicker exterior wall. Therefore, the accelerations were measured at 5 positions on the outer load bearing wall for each position of the standard tapping machine in house C3, see Figure 6.

By studying the difference in results between the exterior walls of house $\mathrm{C} 1$ and $\mathrm{C} 3$, the effect of acceleration level depending of the thickness of the exterior wall can be observed.

\section{ANALYSIS OF THE RESULTS}

The aim of this study was to determine how the structure borne sound is transmitted between different parts of the building. From the test equipment, the equivalent acceleration values in $\mathrm{dB}$ are given at each measuring point in 1/3-octave bands between 10 and $10000 \mathrm{~Hz}$. To calculate a mean equivalent acceleration value, the corresponding accelerations in each point are calculated as

$$
a_{i, f}=\sqrt{\left(a_{r e f, i}\right)^{2} \cdot 10^{\left(L_{e q . f} / 10\right)}}
$$
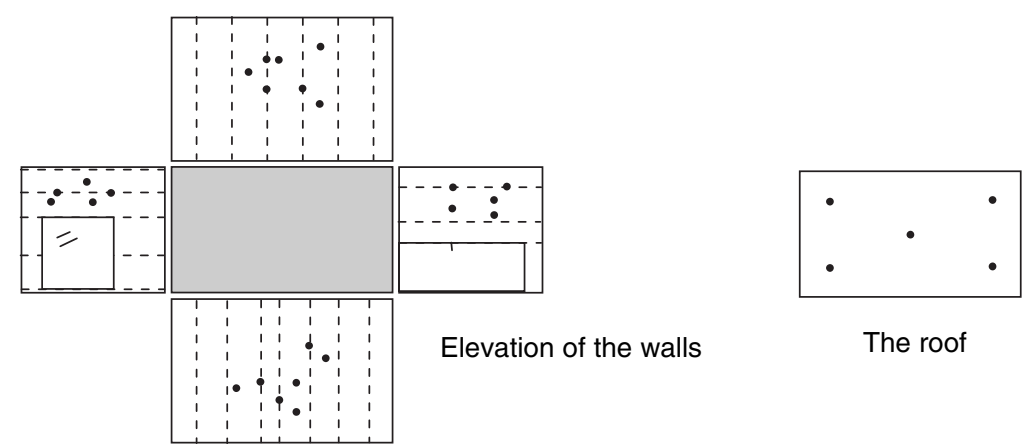

Figure 5. Measured points on the walls and roof of the room on first floor, house $\mathrm{C} 1$. 


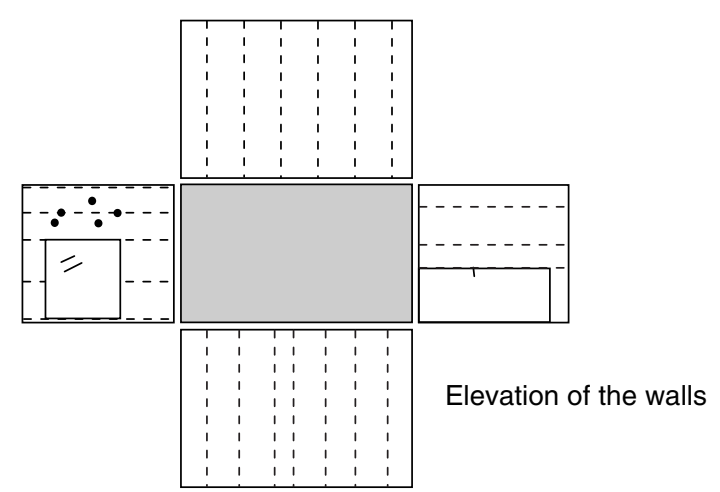

Figure 6. Measured points on the walls of the bedroom on first floor, house C3.

where $a_{r e f, i}$ is the reference acceleration and $L_{e q, f}$ is the equivalent acceleration level at point $i$ for the centre frequency $f$. In addition, a mean value of each wall type was computed as

$$
L_{e q_{i, f}}=10 \cdot \log \left(\frac{1}{m p} \cdot \sum_{n=1}^{m p} \frac{a_{i, f}^{2}}{a_{r e f}^{2}}\right)
$$

where $m p$ is the number of measuring points. A reference acceleration $a_{\text {ref }}=1 \cdot 10^{-6} \mathrm{~ms}^{2}$ is used in all results presented in the remaining part of the paper.

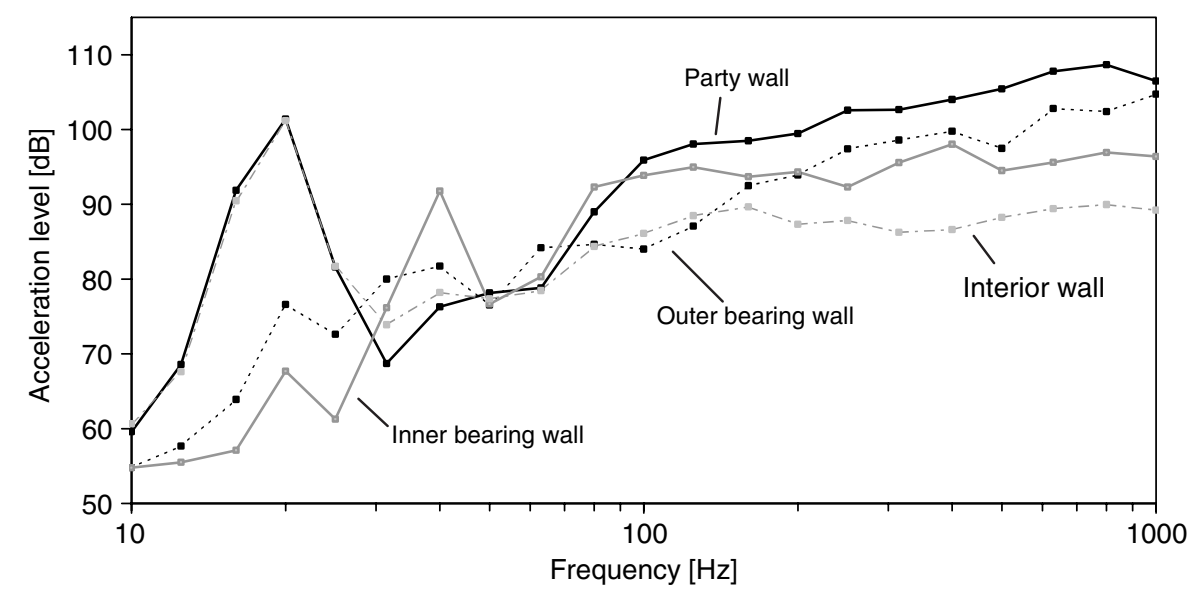

Figure 7. The mean results of the two standard tapping machine positions from the four wall types in house $\mathrm{C} 1$. 
In Figure 7, the equivalent acceleration mean-values for all measuring points and source positions are shown for each wall type in house $\mathrm{C} 1$. The effect of different wall-types can thereby be studied, there is a clear difference between the load and nonload bearing walls. The non-load bearing walls, the party wall and the interior wall, show a pronounced peak in acceleration level in the low frequency region, while the two load bearing walls show a smooth increasing curve over the whole frequency region. Between the non-bearing walls there is an obvious difference in the acceleration level for frequencies above $80 \mathrm{~Hz}$. The party wall has the largest acceleration level of all wall types, while the interior wall shows the lowest acceleration level of the four wall types.

The acceleration from a source in the middle of the room is compared to a source in the corner close to the outer bearing wall and the interior wall, see Figure 4 . The shape of the curves is not very much influenced by the position of the source, see Figure 8 . There are some differences in acceleration levels but neither of the results shows an obvious trend.

The stiffness of the gypsum board is lower than the wall stud stiffness and could have influence on the acceleration levels, see Figure 9. In the frequency interval 90-500 $\mathrm{Hz}$, where impact noise are the main problem, the acceleration levels at the board between the wall studs are higher than directly above the beams, in all cases except for
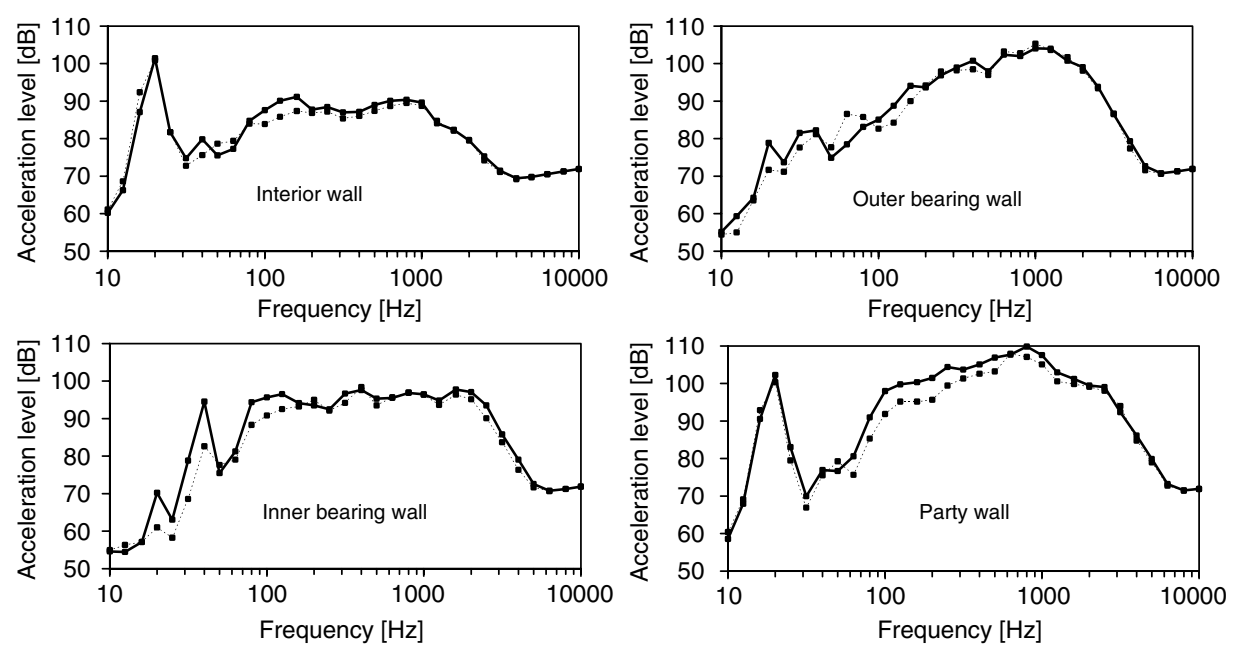

Figure 8. The mean results of each wall in house $\mathrm{C} 1$ for each position of the standard tapping machine. Solid lines shows results where the standard tapping machine is centred in the room, position a. Dashed lines shows results from when it is positioned in the corner of the room, position $b$. 

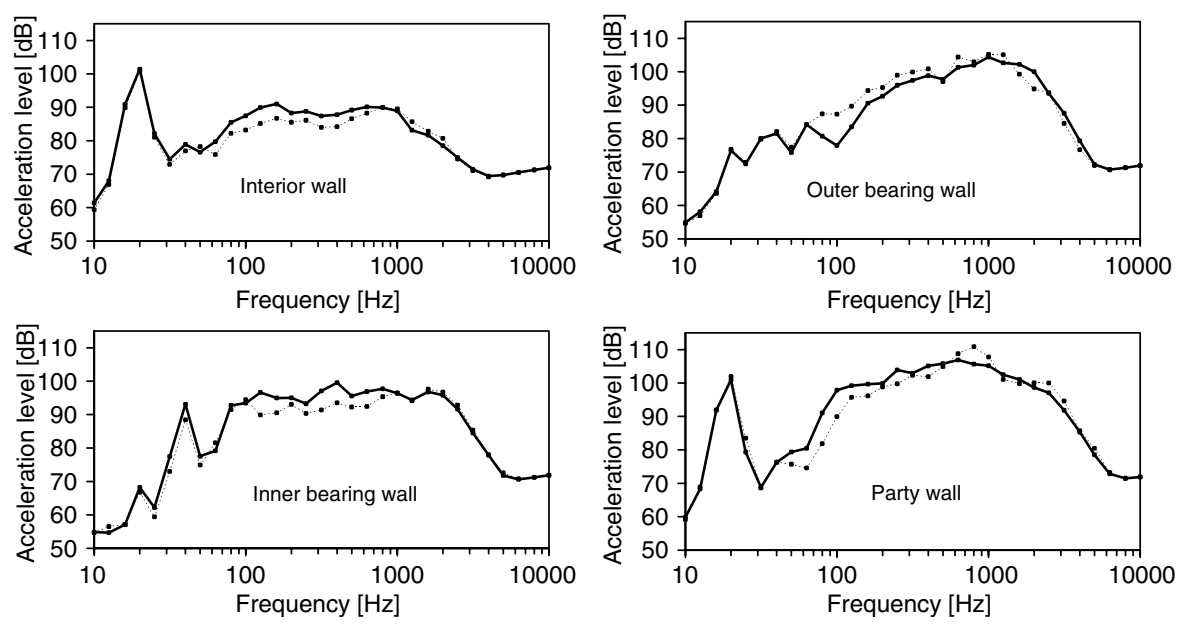

Figure 9. The mean results of the two standard tapping machine positions on the walls in house $\mathrm{C} 1$. Mean values of results on the wall studs are showed with a dotted line and mean values between the studs are showed with a solid line.

the outer bearing wall. The differences depend on the construction. The outer bearing wall is a two-layered wall while all the others have a single layer.

The small room in house $\mathrm{C} 3$ is identical to the one in house $\mathrm{C} 1$ except for the thickness of the installation layer of the outer bearing wall. In Figure 10, the equivalent acceleration mean-values for all measuring points on the two outer bearing walls are

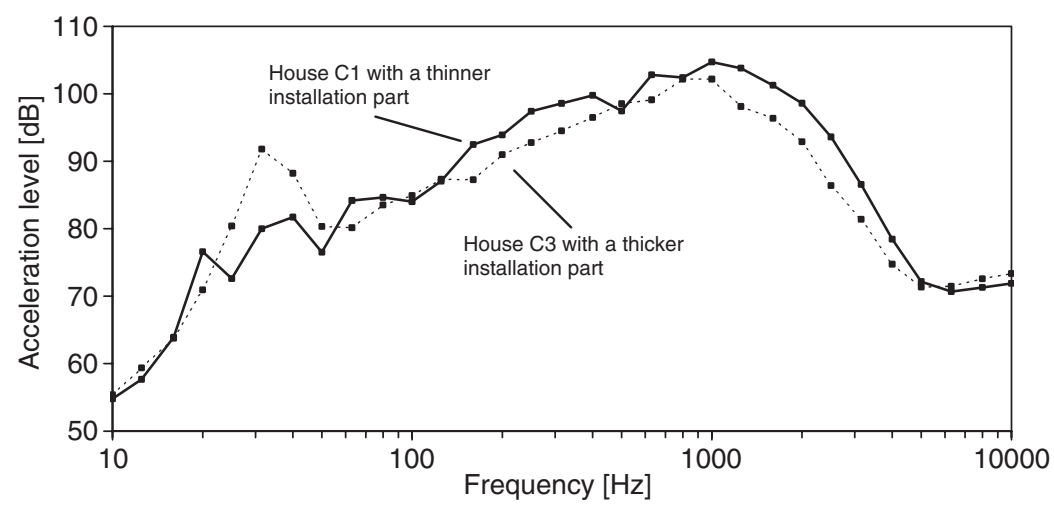

Figure 10. The mean results of the two standard tapping machine positions to the outer bearing walls of the two houses with different thicknesses of the installation part. 
shown. Between $150-5000 \mathrm{~Hz}$ the thicker wall is principally better and the energy is not transmitted through this wall in the same range. However the biggest difference is seen for the frequency region of $20-50 \mathrm{~Hz}$, where the wall with the thicker installation layer shows a much higher peak acceleration level.

\section{DISCUSSION}

It would be interesting to study what influence load or non-load bearing walls has on the acceleration levels in the receiving parts. This can for instance depend on the support systems or on the beam orientation. Halliwell et al. [4] have studied the influence of beam orientation. Their study shows that when solid wood joists are used, the orientation of the beams was not that important. Instead the floor topping or the junction detail is important when the horizontal flanking transmission is studied. If vertical transmission is considered, the wall type is not that important since the direct path are the dominant transmission path. In this study the floor had a good sound insulation and thereby the different walls show large differences in transmission. If this is the case in this study, the support system is probably the main reason for the differences in acceleration levels. In Bolmsvik et al. [5] the influence on connection stiffness is also discussed.

The party wall and the interior wall are non-bearing and show large differences in acceleration levels above $80 \mathrm{~Hz}$. A possible explanation is that the party wall has a strong connection to the floor system, although it is not intended to be a bearing wall. The non-bearing interior wall was build after the house was raised and has therefore a weaker coupling to the floor system.

The results for the different tapping machine positions are similar and show that the position of the source is rather irrelevant. It could be concluded that one source is sufficient in further studies. This also is shown in W. Shi et al. [6].

In the frequency interval between 90 and $500 \mathrm{~Hz}$, where impact noise is the main problem, the acceleration between the wall studs is higher than directly above the beams on all walls except the outer bearing wall. It could be interesting to study whether this depends on the higher damping of the double wall or on the eigenfrequencies of the different wall types.

There are differences in acceleration levels on the walls depending on the thickness of the outer bearing wall. Between 150 and $5000 \mathrm{~Hz}$, the thicker wall does not transmit energy in the same range as the thinner wall. Moreover, in a further study it would be interesting to see what effect a smaller wall stud distance should have on the flanking transmission.

\section{CONCLUDING REMARKS}

Flanking transmission can be assessed by means of accelometers. The main advantage of this approach is that the building parts contributing significantly to the sound pressure in the room can be identified. When measuring with accelometers directly on building parts, the measurements can be undertaken whether the building is completed 
or not. Information about the main causes noise can obtained early and perhaps the problem can be rectified

In the cases studied, it was found that one of the non-bearing walls vibrated the most. It is important to learn more about how the connections affect the flanking transmission.

\section{ACKNOWLEDGEMENT}

The author acknowledges Magnus Ingvarsson, Ingemanssons AB for his help with the measuring and Södra Building Systems AB for financing the tests. He also thanks Stig Hansson, Tyrens AB for support regarding the construction drawings. Torbjörn Ekevid, Växjö University also is acknowledged for good suggestions and comments during the preparation of this paper.

\section{REFERENCES}

[1] BBR 94, chapter 5:8, Boverket, Karlskrona, ISBN 91-7147-130-8, 1994

[2] Acoustics - Sound classification of spaces in buildings - Dwellings SS 25267, Swedish Standard Institute, SIS Förlag AB, Stockholm, Utgåva 3, ICS 91.120.20, 2004

[3] Higher houses with wooden frame (Högre hus med trästomme), ISBN 91-974489-0-7, Elanders Skogs Grafiska, Malmö, 2002, 139 pp

[4] R. E. Halliwell, J. D. Ouirt and T. R. T. Nightingale, Flanking transmission in wood framed multifamily dwellings, Canadian Acoustics / Acoustique Canadienne, 30(3), 32-33, 2002

[5] A. Bolmsvik, P. Hammer and T. Alsmarker, Study of structure-borne sound through different types of junctions, Proceedings of the $8^{\text {th }}$ World Conference on Timber Engineering 2004, Lahti, Finland, ISSN 0356-9403, 2004

[6] W. Shi, C. Johansson, U. Sundbäck, Predicting the impact sound insulation of wooden joist floors by impedance method, Research Report LTU, Luleå, Sweden, ISSN 0347-0881, 1993 
